Available online at www.sciencedirect.com

www.cya.unam.mx/index.php/cya

Contaduría y Administración 60 (S2) 219-249

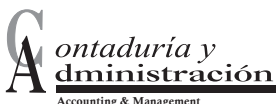

www.contaduriayadministracionunam.mx/

\title{
Las crisis económicas y sus efectos en el mercado de trabajo, en la desigualdad y en la pobreza de México
}

\author{
Economic crisis and its efects on Mexican's labor market, \\ inequality and poverty
}

\author{
Mario Camberos Castroa,", Joaquín Bracamontes Nevárez ${ }^{\mathrm{a}}$ \\ ${ }^{a}$ Centro de Investigación en Alimentación y Desarrollo, Departamento de Economía, México \\ Recibido el 27 de junio de 2014; aceptado el 06 de febrero de 2015 \\ Disponible en internet el 20 de noviembre de 2015
}

\section{Resumen}

Las crisis económicas de México de las últimas 3 décadas tienen como una de sus manifestaciones más graves la pérdida de empleos. Por eso en este trabajo nos proponemos como objetivo mostrar los efectos que han tenido las crisis en México en el crecimiento económico, el mercado laboral, en la desigualdad y en la pobreza desde los años de 1980, pasando por la globalización de los años de 1990 y la financiera reciente. Los resultados encontrados dan cuenta del incremento de la informalidad, la desigualdad y la pobreza a lo largo del período, que coincide con el modelo neoliberal, aplicado para combatir las crisis; por lo tanto, se debe considerar seriamente un cambio de las políticas económicas y sociales hasta ahora aplicadas. Se requiere de reformas económicas más de fondo que impulsen la demanda de trabajo y con ello incrementar empleos mejor remunerados, que beneficien a los individuos de los grupos bajos, con lo que podría reducirse el desempleo, la desigualdad y la pobreza, que ha flagelado a la mayoría de la población de México.

\footnotetext{
* Autorparacorrespondencia.

Correo electrónico: mcamberos@ciad.mx (M. Camberos Castro).

La revisión por pares es responsabilidad de la Universidad Nacional Autónoma de México.

http://dx.doi.org/10.1016/j.cya.2015.05.003

0186-1042/Derechos Reservados (C) 2015 Universidad Nacional Autónoma de México, Facultad de Contaduría y Administración. Este es un artículo de acceso abierto distribuido bajo los términos de la Licencia Creative Commons CC BY-NC-ND 4.0.
} 
Derechos Reservados@2015 Universidad Nacional Autónoma de México, Facultad de Contaduría y Administración.

Este es un artículo de acceso abierto distribuido bajo los términos de la Licencia Creative Commons CC BY-NC-ND 4.0.

Palabras clave: Crisis económica; Mercado laboral; Desigualdad; Pobreza

\begin{abstract}
Mexican economic crisis has generated, along 3 decades, lost of million of formal employments and decreasing real wages as consecuence of informal employment growth. In this framework the objective of this paper is to know the effects of the mexican cyclical crisis on the economic growth, labor market, inequality and poverty, since 1980s debt, global 1990s and financial 2008-2009 crisis. The results arise increasing of labor market informality, inequality and poverty of mexican people, caused not only by crisis, but wronged neoliberals economic y social adjusting policies implemented against it. By the way, it is necesary deep changes in the above model, such as, economic reforms to afford formal labor demand, employment and salaries increasing, necesary condition for diminishing inequality and poverty of the most mexican people.

All Rights Reserved (C) 2015 Universidad Nacional Autónoma de México, Facultad de Contaduría y Administración.

This is an open access item distributed under the Creative Commons CC License BY-NCND 4.0.
\end{abstract}

Keywords: Economic crisis; Labor market; Inequality; Poverty

\title{
Introducción
}

En el marco de la globalización, las crisis económicas de las últimas décadas y particularmente la crisis actual tiene como una de sus manifestaciones más graves, la pérdida de empleos (Stiglitz, 2012 y Krugman, 2012). Al respecto, un informe de la OIT (ILO, 2013) señala que en la crisis del 2009 se perdieron más de 50 millones de empleos en el mundo, $0.9 \%$ del total, de los cuales cerca de 7 millones correspondían al mercado de trabajo de EE.UU., cuya tasa se acercó al 10\% (USA, Labor Department, 2009) y tardó más de 4 años en recuperarlos y reducirla nuevamente al 6.3\% (USA, Labor Department, 2014). Es importante señalarlo, porque ello provocó en México, debido a su dependencia económica con el país del Norte - particularmente del sector industrial-, la pérdida de poco más de 1 millón de empleos desde septiembre del 2008, llegando la tasa de desempleo al 5.6\% (INEGI, 2009), muy por encima del 3\% registrado antes de la crisis (INEGI, 2007) y que actualmente sigue sin recuperar del todo tales niveles (INEGI, 2014). 
Por otra parte, la misma OIT (ILO, 2012) muestra cómo la crisis ha traído consigo el inevitable aumento en los niveles de desigualdad y pobreza en lo primera década del siglo XXI. Para dar cuenta de ello, el Programa de las Naciones Unidas para el Desarrollo señalaba en su informe (PNUD, 2010) que 10 de los 15 países más desiguales del mundo se localizan en América Latina y el Caribe, siendo México uno de ellos y en el que se hizo más patente la desigualdad, al grado que el ingreso del $10 \%$ más rico pasó de ser 19.3 veces mayor que el del $10 \%$ más pobre en 1984, a 33.5 veces en el 2008 (Tello, 2010; Camberos, 2012; Szekely, 2005); mientras que en el país se comprobó el aumento del nivel de pobreza por efecto de la crisis reciente que arrojó a 12 millones más a la pobreza (ITESM, 2010; Valero-Gil y Valero, 2008), para superar nuevamente los 50 millones de pobres en el 2012 (CONEVAL, 2013), que contrasta con la aparición, en el mismo período, de la mayor cantidad de mexicanos en la lista de las personas más ricas del mundo (Blankfeld, 2011), a pesar de que un estudio reciente del Banco Mundial apunta al incremento de la clase media en américa Latina (Ferreira, et. al., 2013), tal vez no lo sea tan cierto para México, de otra manera ¿cómo se podría explicar el aumento del número de pobres?

Todos estos resultados han llevado a considerar con mayor interés el problema de la desigualdad conjuntamente con la pobreza y la vulnerabilidad y a la participación de los estados nacionales y los organismos supranacionales como las Naciones Unidas (UNDP, 2014), el Banco Mundial, (World Bank, 2013) y el Foro Económico Mundial de Davos (2014) en la búsqueda de soluciones.

En este marco nos proponemos como objetivo mostrar los efectos que han tenido las crisis en México desde los años de 1980, pasando por la globalización de los años de 1990 y la financiera reciente, en el crecimiento económico, el mercado laboral, en la desigualdad y en los niveles de pobreza. Para ello, analizaremos inicialmente la situación económica del país y el nuevo modelo de desarrollo implementado, importante considerarlo, toda vez que marcó el inicio de una nueva etapa del desarrollo económico de México que dura ya 3 décadas. En seguida mostraremos el impacto de las crisis en el crecimiento económico y el mercado laboral y las medidas de política económica que se implementaron para superar la crisis. Posteriormente analizamos el impacto en la desigualdad, para subsecuentemente analizar cómo pueden los aumentos en la desigualdad traducirse en incrementos en los niveles de pobreza. Finalmente tenemos las conclusiones y recomendaciones. 


\section{El efecto de las crisis en el crecimiento económico y el mercado laboral}

Las crisis recurrentes iniciadas a principios de 1982, que se repitieron a lo largo de toda la década, a causa de la caída de los precios del petróleo, las exigencias impuestas por el pago puntual de la deuda externa, agravada por la sacudida de los mercados de capital cada vez que aumentaba la tasa de interés el Sistema de la Reserva Federal de EE.UU. (FED por sus siglas en inglés), la apertura de la economía mexicana al exterior y las políticas de ajuste para equilibrar las cuentas con el exterior y la privatización son las características más relevantes del nuevo modelo.

La implementación del nuevo modelo acompañado de las reformas modernizadoras, con la apertura comercial a ultranza de México al mundo y los ajustes económicos que fueron implementados por las administraciones gubernamentales de México desde 1982 para lograr el cambio estructural anhelado, se veían como una respuesta novedosa a la crisis, incluso se llegó a pensar por un grupo de pensadores influyentes en su momento, que sería la solución para evitarlas en lo futuro. En esta corriente de autores se inscribe Aspe (1993), Villarreal (1988), Zabludovsky (1993) y Bravo (1993), la apertura se convertía en el punto central de la nueva estrategia del desarrollo, toda vez que liberaba a la economía mexicana de las ataduras impuestas por la política proteccionista y estatista, implementadas durante más de 3 décadas por los gobiernos de corte nacionalista.

Existe también, por el otro lado de la moneda, un conjunto de autores que analizó los efectos negativos de los llamados ajustes económicos en el gasto en salud y educación, que se tradujeron en los conocidos como «los costos sociales», en el sentido de que fueron medidas que se tradujeron en desempleo, informalidad en el empleo o subempleo, caída del salario real y descuido de los sistemas de seguridad social, que provocaron aumentos en la desigualdad (Alba, 1993; Lustig, 1999; Pánuco y Székely, 1999; Camberos, 1994) y en la pobreza (Boltvinik, 1994; Lustig, 1993 y Levy, 1991) y que se convirtieron, como las crisis y las recesiones, en una constante a lo largo de las décadas de 1980, 1990 y 2000.

La apertura comercial tiene especial importancia en el inicio de este período, porque constituía -así se pensaba en esta nueva era del desarrollo- una señal en el camino, o más bien en el túnel, por la incertidumbre que envolvía a la economía mexicana, por el cual transitaría, como se anotó arriba, a lo largo de las siguientes 3 décadas. A continuación revisaremos los aspectos nodales de esta apertura y los efectos, primero en las cuentas con el exterior, principal preocupación del gobierno de México durante la crisis, y luego como su impacto en el crecimiento, el empleo y los llamados «costos sociales» del ajuste. 


\section{La apertura comercial y la globalización}

La apertura se acelera inicialmente por las presiones de los organismos financieros internacionales, principalmente el FMI y el Banco Mundial, responsables del rescate de las economías que enfrentan problemas de cumplimiento de pagos con sus acreedores, cuando ponen en riesgo el equilibrio de los mercados internacionales, como era el caso de México. Así, a cambio del rescate, tendrían que implementarse ajustes supervisados por los organismos mencionados. Se exigió al gobierno mexicano que cambiara su política proteccionista de la economía por una de apertura al mercado internacional, y es el Presidente Miguel De La Madrid a quien le toca acelerar el proceso de apertura (Tello, 2009).

Ya en el Plan de Desarrollo de 1983 se contempla la reforma arancelaria que abre las puertas de México al mercado mundial; mientras que, en el Programa Nacional de Fomento a las Exportaciones se plantean los mecanismos para lograrlo (Bravo, 1993 y Zabludovsky, 1993).Acorde con el Programa, durante 1984 se inicia el desmantelamiento del sistema de permisos previos para importar, logrando desgravar 2,844 fracciones en ese año, cerca del $25 \%$, proceso que se aceleró en el siguiente año hasta desgravar 7,252 fracciones, llegando a 11,880 en 1988, prácticamente el total (Bravo, 1993).

La adhesión de México al desaparecido Acuerdo General de Aranceles y Comercio -ahora convertido en la Organización Mundial de Comercio- en 1986, constituyó, sin duda, el factor cualitativo que requería el nuevo modelo, pues casi de manera inmediata se redujo el arancel de los bienes de consumo a un máximo del $20 \%$. Un año después las fracciones arancelarias se redujeron a 329 y el arancel máximo pasó de 50\% a 29\%, con un promedio de 9.7\% (Gittli, 1990).

Al final de la década de 1980, se había eliminado prácticamente de la política comercial con el exterior el factor discrecional que representaban los permisos de importación, vigente por más de 3 décadas, quedando la política arancelaria como el marco de intercambio con el exterior. El siguiente paso se dio inmediatamente. La década de los 1990 trajo consigo globalización, y con ella la firma de tratados comerciales iniciados con el Tratado de Libre Comercio con EE.UU. y Canadá (TLC) en 1993, al que le siguieron los de Chile y la Unión Europea, Japón como los más relevantes, la apertura ya no fue producto de las presiones internacionales como ocurrió una década atrás, sino que el gobierno mexicano lo convertía en parte esencial de una estrategia deliberada del desarrollo económico de México, toda vez que mediante estos tratados se eliminaron prácticamente todas las barreras arancelarias convirtiendo a México en uno de los países con el mayor grado de globalización económica, por llamarlo de una manera más correcta. 


\section{El crecimiento económico}

Si el sector externo no mostraba los resultados del todo esperados al final de la década, en cuanto a la eliminación de las presiones externas al resto de la economía no le fue mejor, como se observa en la tabla 1 (infra) que ofrece una síntesis de los indicadores de la economía: el crecimiento económico, el empleo, el salario y el gasto social, que servirán para conocer el impacto de las crisis.

En primer lugar el crecimiento del PIB muestra un comportamiento irregular en el sentido en que junto con los aumentos leves y excepcionalmente elevados observados para algunos años, en 3 se registraron reducciones, como en 1982, 1983 y 1986; mientras que, la tasa media de crecimiento anual del PIB apenas llegó al $1.55 \%$, muy por debajo del crecimiento de la población, que lo hizo a una tasa de $1.95 \% ;{ }^{1}$ por ello, la verdadera dimensión del retroceso de la economía se registra en el crecimiento económico o crecimiento del PIB per cápita real (tabla 1, $4^{\mathrm{a}}$ columna), cuyo nivel más alto equivalente a 3,640 dólares de 1980 lo alcanzó en 1981 , en tanto que el resto de la década se redujo a una tasa de $-1.34 \%$.

En las décadas de 1990 y 2000 el crecimiento económico no fue mucho mejor. La misma tabla 1 muestra caídas mayores en 1995 de $8.53 \%$ y de $8 \%$ en el 2009, pero además hay otros años en los que también se registran retrocesos, de tal suerte que el crecimiento anual per cápita en las tres décadas no alcanza siquiera el $1 \%$. Estos resultados obviamente produjeron efectos negativos en el empleo, la desigualdad y la pobreza, como lo demostraremos en los apartados siguientes.

\section{Los costos sociales: desempleo, salario, informalidad y gasto social}

Los ajustes económicos impactaron fuertemente el mercado laboral. Por una parte, la orientación del mercado al exterior inició el rompimiento de las cadenas productivas, particularmente en los sectores de bienes de consumo y en el campo, por las facilidades otorgadas para su importación, una vez eliminados los permisos. Pero también el adelgazamiento del Estado y luego la «privatización» impactaron al empleo, cuyos efectos podemos evaluar por medio de 3 indicadores que aparecen en la misma tabla 1: a) la tasa de desempleo abierto o desempleo, b) el salario mínimo real, c) el ingreso medio real de los empleados; y como corolario, d) la informalidad.

\footnotetext{
${ }^{1}$ Este dato se obtiene a partir de los censos de población de 1980, de la antigua Secretaría de Programación y Presupuesto y el de 1990, del INEGI, México.
} 


\section{El desempleo}

La tasa de desempleo constituye uno de los indicadores macroeconómicos más importantes, cuyas estadísticas oficiales más confiables empezaron a recopilarse apenas en la década de 1970 y que adquirieron mayor relevancia a raíz de las crisis el subempleo y la informalidad.

Del análisis de los resultados sobre el mercado de trabajo que aparecen en la misma tabla 1 (columna 6) se destaca la baja tasa de desempleo, menor al 4\%, en los años que precedieron a la primera crisis de la década de los años 1980; como también su crecimiento hasta llegar al 6\%, como una de las manifestaciones de la crisis que mayor perjuicio causa a la población, porque la deja sin una fuente segura de ingreso y en riesgo de reducir su bienestar.

Un aspecto por demás importante, que marca el inicio de este período, es la reducción de manera drástica del trabajo asalariado, junto con su participación en el PIB que siguió a la crisis de 1982, y que continuaría a lo largo 3 décadas.

Tabla 1

México. Efectos de las crisis en el crecimiento y en el mercado de trabajo.

\begin{tabular}{ccccccccc}
\hline Años & $\begin{array}{c}\text { Población } \\
\text { (miles) }\end{array}$ & $\begin{array}{c}\text { PIB* } \\
\text { (tmca) }\end{array}$ & $\begin{array}{c}\text { PIB } \\
\text { Pépita } \\
\text { cápita }\end{array}$ & $\begin{array}{c}\text { Tasa de } \\
\text { inflación } \\
(\%)\end{array}$ & $\begin{array}{c}\text { Tasa de } \\
\text { desempleo } \\
(\%) * *\end{array}$ & $\begin{array}{c}\text { Salario } \\
\text { mínimo } \\
\text { (índice) }\end{array}$ & $\begin{array}{c}\text { Salarios } \\
\text { contractuales } \\
\text { (índice) }\end{array}$ & $\begin{array}{c}\text { Gasto } \\
\text { social } \\
\text { Per cápita } \\
\text { (índice) }\end{array}$ \\
\hline 1980 & 66,847 & 9.2 & 5.71 & 20 & 4.3 & 100 & 100 & 100 \\
1981 & 68,164 & 8.76 & 6.67 & 28 & 3.9 & 102 & 102 & 114 \\
1982 & 69,508 & -1.3 & -2.47 & 59 & 3.9 & 98 & 100 & 115 \\
1983 & 70,876 & -4.2 & -6.05 & 102 & 6 & 74 & 77 & 81 \\
1984 & 72,272 & 3 & 1.61 & 66 & 5.13 & 69 & 73 & 74 \\
1985 & 73,696 & 2.8 & 0.6 & 58 & 4.9 & 61 & 73 & 74 \\
1986 & 75,148 & -4 & -5.61 & 86 & 5.1 & 66 & 66 & 65 \\
1987 & 76,628 & 1.2 & 0.11 & 44 & 4.4 & 65 & 75 & 69 \\
1988 & 78,138 & 0.8 & -0.71 & 114 & 4.3 & 51 & $69 * *$ & 27 \\
1989 & 79,677 & 1.4 & 2.1 & 20 & 4.3 & 50 & $67 * *$ & 25 \\
1990 & 81,247 & 4.22 & 3 & 19.5 & 2.7 & 45 & $64 * *$ & 25 \\
1991 & 83,132 & $3.6^{(+)}$ & $1.27(-)$ & $199^{(+)}$ & 2.6 & $46.0^{(+)}$ & $57.5^{(+)}$ & $* * *$ \\
1992 & 85,060 & 2.1 & -0.23 & 11.9 & 2.8 & 45.1 & 56.3 & $* * *$ \\
1993 & 87,033 & 0.9 & -1.43 & 8.01 & 3.3 & 44.9 & 56.3 & $* * *$ \\
1994 & 89,053 & 4.4 & 2.07 & 7 & 3.73 & 44.1 & 54.9 & $* * *$ \\
1995 & 91,158 & -6.2 & -8.53 & 52 & 6.27 & 37.5 & 45.6 & $* * *$ \\
1996 & 92,349 & 5.2 & 3.85 & 28 & 5.77 & 35.7 & 43.4 & $* * *$ \\
1997 & 93,596 & nd & nd & 5.7 & 4.01 & 34.7 & 43.3 & $* * *$ \\
1998 & 94,859 & 4.9 & 3.55 & 19 & 3.29 & 34.1 & 43.7 & $* * *$ \\
1999 & 96,140 & nd & nd & 12.3 & nd & 32.7 & 43.6 & $* * *$ \\
\hline
\end{tabular}




\begin{tabular}{lllllllll}
\hline Años & $\begin{array}{c}\text { Población } \\
\text { (miles) }\end{array}$ & $\begin{array}{c}\text { PIB* } \\
\text { (tmca) }\end{array}$ & $\begin{array}{c}\text { PIB } \\
\text { Per } \\
\text { cápita }\end{array}$ & $\begin{array}{c}\text { Tasa de } \\
\text { inflación } \\
(\%)\end{array}$ & $\begin{array}{c}\text { Tasa de } \\
\text { desempleo } \\
(\%) * *\end{array}$ & $\begin{array}{c}\text { Salario } \\
\text { mínimo } \\
\text { (índice) }\end{array}$ & $\begin{array}{c}\text { Salarios } \\
\text { contractuales } \\
\text { (índice) }\end{array}$ & $\begin{array}{c}\text { Gasto } \\
\text { social } \\
\text { Per cápita } \\
\text { (índice) }\end{array}$ \\
\hline 2000 & 97,483 & 6 & 4.65 & 9 & 2.28 & 30.9 & 44.8 & $* * *$ \\
2001 & 98,604 & 0 & -2 & 4.4 & 2.28 & 29.1 & 46 & $* * *$ \\
2002 & 99,738 & 0.8 & -0.34 & 5.7 & 2.74 & 28.7 & 46.3 & $* * *$ \\
2003 & 100,885 & 1.4 & 0.26 & 4 & 3.09 & 28.2 & 46.4 & $* * *$ \\
2004 & 102,045 & 4.2 & 3.06 & 5.4 & 3.82 & 27.9 & 46.3 & $* * *$ \\
2005 & 103,263 & 3.1 & 1.96 & 3.2 & 3.2 & 28.3 & 46.7 & $* * *$ \\
2006 & 104,932 & 4.9 & 3.1 & 3.9 & 3.6 & 27.9 & 46.7 & $* * *$ \\
2007 & 106,674 & 3.2 & 1.4 & 3.8 & 3.2 & 28 & 47.2 & $* * *$ \\
2008 & 108,444 & 1.2 & -0.6 & 6.5 & 3.97 & 27.6 & 47.5 & $* * *$ \\
2009 & 110,244 & -6.2 & -8 & 3.6 & 5.45 & 27 & nd & $* * *$ \\
2010 & 112,336 & 5.4 & 3.6 & 4.4 & 5.39 & nd & nd & $* * *$ \\
\hline
\end{tabular}

*Tasa media de crecimiento anual del producto interno bruto.

***Gasto en educación y salud. A partir de 1990 se crearon los programas para combatir la pobreza como Pronasol en la administración de Carlos Salinas, Progresa con Ernesto Zedillo y Oportunidades con Vicente Fox, y continuado por el Presidente Felipe Calderón, a través de los cuales se canalizó parte del gasto social, por eso no son del todo comparables los períodos.

(+) A partir de ese año tomados de Tello (2010).

nd: información no disponible.

Fuente: estimaciones propias basadas en Camberos, 1994 (p. 136-138) y Camberos, 1995 (p. 149). Para el desempleo de la década de 1980 y 1990 (1990 y 1995), Cámara de Diputados, CESOP (2004) e INEGI (2008 y 2011); Población (tmca) 1980-1990 = 1.97; 1990-1995 = 2.33\%, 1995-2000 = $1.35 \% ; 2000-2005=1.14 \%$ y $2005-2010=1.66 \%$, en función de INEGI, conteo de población (1995 y 2005) y censos de población y vivienda (1980, 1990, 2000 y 2010).

Sobre este asunto Nora Lustig revela que la proporción de los asalariados bajó de $83.4 \%$ en 1982 a $76.2 \%$ en 1985 , mientras que el número de trabajadores por cuenta propia aumentaba de $12.1 \%$ a $15 \%$, y el de los trabajadores familiares no remunerados aumentaba de $2.1 \%$ a $4.6 \%$. Cabe agregar que la proporción de asalariados continuó disminuyendo a razón de 1 a 2 puntos porcentuales (Lustig, 1993), en la medida que el empleo informal llegó al $11 \%$ a finales de la década (Tello, 2010). Más aún, de acuerdo al criterio que menciona Lustig, la primera crisis de la globalización que sufrió México en 1995 empeoró la situación de los trabajadores, pues la proporción de quienes recibían remuneración respecto a la población económicamente activa (PEA), que incluye empleados, desempleados y subempleados (INEGI, 2009) llegó a cerca del 23\%, proporción que se mantuvo hasta el principio del siglo XXI, de acuerdo a estadísticas que presentan Hernández y Velázquez (2003). 
Cabe decir que el desempleo abierto se redujo a principios de la década de 1990; sin embargo, se intensificó el subempleo y la informalidad tomó carta de naturalización, como revisaremos con más detalle en el apartado de la informalidad. Lo que si se convirtió en un fenómeno recurrente es el alza del desempleo con las crisis, tanto de 1995, originada internamente, como la más reciente del 2009, la primera del mundo globalizado. En este año la tasa de desempleo en México llegó a cerca del 6\% (INEGI, 2010), incremento fuerte si consideramos que en el año 2007, que precedió a la crisis, apenas rebasaba 3\% (INEGI, 2007).

A diferencia de lo ocurrido en las crisis anteriores, la más reciente impactó fuertemente a los estados del Norte de México: Baja California, Sonora, Chihuahua, Coahuila, Nuevo León y Tamaulipas, que rebasaron el 6\% (INEGI, 2010), en contraste con las entidades del Sur y Sureste, como Chiapas, Guerrero, Oaxaca, Veracruz y Yucatán, que registraron tasas de desempleo menores al 3\% y Michoacán $4.10 \%$ (INEGI, 2009), otrora más afectadas cuando las crisis eran originadas por factores internos.

\section{La caída del salario real}

En esta relación desempleo-salario real existen varios puntos a destacar en la citada tabla 1 -columnas 7 y 8 (supra)- para objeto de nuestro trabajo:

$1^{\circ}$. Paralelamente al aumento del desempleo, se puede observar la caída del salario real, medido por la pérdida de valor real del salario mínimo y del ingreso medio de todos los empleados, con base al índice $1980=100$, para todos los años posteriores a la crisis -excepto para 1987 en que repunta, pero luego se desploma también- hasta quedar reducido a la mitad de su valor el salario mínimo y al $64 \%$ el salario medio. Al respecto, Francisco Alba anotaba desde las crisis de los años 1980, que en lo que se refiere a los salarios, el deterioro de las remuneraciones de los trabajadores industriales llegó en 1987 a representar el 72.8\% de las de 1980, en tanto que el deterioro de los salarios mínimos cayó al 60.6\% del de 1980 (Alba, 1993. p. 189-190). En otro trabajo de Gil y Ramos, 1988 (p. 429), se confirma también el deterioro del salario real del sector manufacturero hasta representar solo el 63\% del que tenía en 1980.

Existen varias explicaciones sobre la caída del salario. Una se fundamenta en la teoría neoclásica de la distribución con arreglo a la productividad, de la cual se desprendería que los salarios en México cayeron por efecto de la caída en la productividad (INEGI, 2013a). Estudios que analizan la evolución de la productividad en México en el período señalan que en la manufactura, la actividad más regulada por los salarios contractuales, la productividad del trabajo se incrementó levemen- 
te en los primeros años del TLC 0.4\% 1995-1999 (Casanueva y Rodríguez, 2009), pero lo hizo en 33\% en el período 1985-1990; mientras que López (2003) también en un estudio para la manufactura por regiones que abarca el período 1993-1999, encuentra aumentos en la productividad en las regiones Norte, Centro, Ciudad de México, pero no en el Sur, que coincide con los respectivos incrementos en la productividad, encontrados en otros estudios que aquí mencionamos.

Al respecto, Varella y Cabral (2007), en un estudio de la manufactura antes y después del TLC para el período 1984-2000, estimaron aumentos en la productividad en la década de 1990.

Por su parte, el Centro de Investigación para el Desarrollo A.C. (CIDAC, 2011) en un trabajo más reciente calculó, por medio de una función producción, con datos de la Organización para el Desarrollo Económico (OCDE, por sus siglas en inglés), que la productividad del trabajo y sus resultados contrastan con los mostrados arriba, pues justamente en los años que siguieron a la firma del TLC, desde 1994, la productividad del trabajo se derrumbó a su nivel más bajo de las últimas 3 décadas y recuperó hasta el año 2000 el nivel alcanzado en 1991, año de inicio de la serie, registrando crecimiento continuo durante prácticamente el resto de la década hasta 2009; sin embargo, la productividad acumulada durante el período, aclara el CIDAC (2011), fue de solo $2.1 \%$.

También hay que mencionar que un estudio comparativo de México y Chile, realizado por Bourguignon (en Varella y Cabral, 2007), encontró una declinación en la productividad de México en la década de 1980 y principios de los años de 1990.

Parece más bien que la caída del salario puede ser explicada por el aumento del desempleo, y luego, por la generalización del subempleo y la informalidad desde mediados de la década. Esta relación empírica se ajusta más al modelo de la Curva de Phillips original (Dornbusch y Startz, 2000) que establece una relación inversa entre desempleo y salario: a mayor desempleo, que significa mayor oferta, baja su precio, esto es, baja el salario, que es la forma que reviste en el mercado; sin embargo, su reducción es detenida, pero no de la forma como lo explican los clásicos con salarios flexibles hasta equilibrar los mercados, sino más bien por medio de la legislación laboral, que establece como límite inferior el salario mínimo, una suerte de rigidez salarial estilo keynesiana, que obliga su observancia en la contratación formal.

$2^{\circ}$. La realidad de las crisis de la economía mexicana que generan grandes masas de desempleados contrasta con las estadísticas que muestran como en la segunda parte de la década el desempleo se atenúa; sin embargo, el salario continúa disminuyendo. En el deterioro del salario real también jugó un papel importante 
el proceso inflacionario, particularmente en la década de los 1980s, cuando en los años de 1983 y 1988 (tabla 1 [columna 4]), se alcanzaron inflaciones anuales de 3 dígitos, que aunado a la política de contención salarial, produjo ajustes de los salarios, contractuales principalmente, por debajo de la inflación esperada, que siempre fue menor a la real. Ésta política se mantuvo con mayor o menor rigidez hasta la presente década, lo cual explica el que el salario real, y en general los ingresos de los trabajadores, no se hayan recuperado 25 años después de iniciada esa política.

Con el propósito de abundar en evidencias empíricas sobre el deterioro del mercado de trabajo mexicano en la década de la globalización, tomamos los datos de un trabajo de Hernández y Velásquez (2003, p. 216), y con ellos estimamos que la capacidad de compra de los trabajadores de menores ingresos, que incluye asalariados e informales, se deterioró en $37 \%$; mientras que el ingreso promedio de todos los trabajadores sujetos a contratos lo hizo en $21 \%$. Cualesquiera sean los resultados que se tomen comparado con los que se registraron al inicio del actual período de análisis, las conclusiones que se desprenden son claras, muestran el grave deterioro de grandes capas de población ocupada, que una vez fue asalariada y muy probablemente ahora debe ser parte de la informalidad del mercado laboral (Huesca, 2005), lo cual hace esperar fuertes aumentos en la pobreza, que habremos de probar en los siguientes apartados.

Estos resultados evidencian que la formalidad, sujeta a la legislación laboral mexicana, es solo una parte de la realidad del mercado laboral, la otra es la informalidad, que coadyuva a explicar, en el caso de México, la caída del salario real, razón por la cual pasamos en seguida a tratarla.

\section{La informalidad del mercado de trabajo}

La parte no formal del mercado se puede definir como aquella población subempleada que percibe un salario menor al que marca la ley, u ocupada que no está sujeta a una relación contractual, y que a falta de seguro del desempleo se muestra dispuesta a trabajar a cambio de un pago, por bajo que este sea, o bien decide autoemplearse antes que engrosar las filas del ejército laboral de reserva. Con estas características, es lógico comprender por qué la informalidad se convierten en un velo que oculta la verdadera magnitud del problema del desempleo (Tockman, 1993), no solamente en México y América Latina, sino que se ha vuelto común en prácticamente todos los países pobres o subdesarrollados del mundo, a pesar de la modernización de la economía mundial, o quizá como uno de sus efectos, en los inicios del siglo XXI -así parecía señalarlo las estadísticas de la OIT (2001). 
Las evidencias empíricas del mercado de trabajo en México encontradas por diferentes autores también dan cuenta de este proceso de informalización que no se detuvo con la modernización de la economía, ni con el cambio estructural, tampoco con la globalización, sino que continuó a lo largo de las siguientes 2 décadas. Por ejemplo, F. Alba (1993, p. 190) señala que entre 1979 y 1986 el porcentaje de trabajadores asalariados se redujo de $81 \%$ a $75.5 \%$ entre los hombres y de $80.1 \%$ a 77.9 \%entre las mujeres; en cambio el empleo por cuenta propia pasa de $15.3 \%$ a $19.2 \%$ entre los hombres y de $18.8 \%$ a $21 \%$ entre las mujeres, se piensa que la mayor parte de estos últimos 7 puntos porcentuales en los que se incrementaron la últimas categorías, representen ocupación informal, que tiene la virtud estadística de reducir la tasa de desocupación abierta.

Para la década que marca el inicio de la globalización moderna, un estudio da cuenta que la informalidad medida con el método de Jusidman y Eternod (1993), la cual aumentó en la primera mitad de la década de 1990 al pasar de $51.8 \%$ en 1990 a 54\% en 1996 (Soria, 2001). En otro trabajo que toma como período de referencia la segunda mitad de la década, se estimó que entre 1995 y el año 2000 se crearon 6.7 millones de empleos, de los cuales, 3.3 millones fueron formales, bajo el criterio de la formalidad de pertenecer al IMSS, ISSSTE o contar con cualquier otro sistema de seguridad social reconocidos legalmente (BBVA-Bancomer, 2001, p. 35). De lo anterior se desprende, que los restantes empleos, poco más del 50\%, resultaron ser informales.

Un análisis para toda la década considerando la informalidad bajo 2 criterios: a) por no pertenecer a un sistema de seguridad social legalmente reconocido; y b) por percibir un ingreso menor a 3 salario mínimos en el año 2000, que de acuerdo al Consejo Nacional de Población (CONAPO, 2001) resultaba, a inicios del siglo XXI, insuficiente para alcanzar un bienestar mínimo, estimó en el primer caso que el $60 \%$ de la población empleada era informal; mientras que en el segundo, resultó la informalidad en 70\% (Camberos y Yañez, 2003, p. 31-39).

Los datos que recogen el efecto de la crisis más recientes en la informalidad del mercado laboral es por un lado Tello (2010) quien la estima para el año 2008 en 55\% el porcentaje de trabajadores urbanos en empresas formales, pero al margen de toda prestación de ley; por otro lado, en la actualidad la informalidad llega hasta el 60\% (ILO, 2013; ILO, 2011) e INEGI 2013b), niveles preocupante, pues ello significa que la mayoría de la población trabajadora se encuentra marginada de los sistemas de seguridad social y con un futuro incierto.

Cabe señalar en este punto que el nuevo sistema de contratación, outsorcing, puede eximir a cierto tipo de empresas, o algunas operaciones de la misma empresa, del pago de prestaciones a los trabajadores mediante la contratación a destajo, que pudie- 
ra asimilarse como una de las formas que adopta la flexibilización del trabajo en el siglo XXI. ¿Será este el futuro del mercado laboral mexicano?

\section{La caída del gasto social}

Un último punto a tratar en este apartado se refiere al impacto de las políticas de ajuste en relación al uso de los recursos destinados a proteger algunas de las necesidades básicas de la población, como educación y salud, particularmente de la población que posee escasos recursos. En este aspecto destaca el hecho de que el gasto público se redujo en los años que siguieron a la crisis de 1982 (tabla 1, [última columna]) en 7.6\%, como respuesta a las exigencias que impuso, principalmente, el pago puntual de la deuda externa que creció en $25.5 \%$ entre 1983 y 1988 (Lustig, 1993, p. 218).

El gasto social en educación y salud, respecto al gasto público, sufrió sensibles recortes, que aunado a la reducción del gasto público mismo, por la caída a su vez del PIB en el período señalado, explican la reducción todavía más drástica del gasto social destinado a las personas, que se redujo a una tasa anualizada de $-13.1 \%$ a lo largo de una década. Resulta de la mayor relevancia señalar que esta medida se convirtió en una práctica del gobierno mexicano cada que se presentaba una crisis o recesión en México, solamente que se veía disfrazada en cada uno de los sexenios con programas de combate a la pobreza como el Programa Nacional Solidaridad (PRONASOL, Salinas, 1989), o focalizada cono el Programa de Educación, Salud y Alimentación (PROGRESA, Zedillo, 1995) y OPORTUNIDADES (Sedesol, 2003).

Este último programa, iniciado con Fox en el 2001, destinó recursos para los pobres por 36 mil millones de pesos en el año 2006 (Bracamontes et al. 2011), lo cual significa que de no haber existido errores de focalización, es decir, de haber llegado en su totalidad a los pobres, cada uno hubiera recibido en el año transferencias monetarias para alimentación, salud y educación por $\$ 818.18$, o bien $\$ 68.12$ mensuales, claramente insuficientes para complementar la escasez de recursos que en promedio requerían los pobres para abandonar su situación de precariedad -como lo veremos en el apartado siguiente-, pero además con limitada incidencia en la desigualdad, toda vez que esta mostró elevados niveles a lo largo de las 3 décadas analizadas, comparado con 1977 y 1984, cuando observó los más bajos niveles.

Una nueva modalidad del gasto social la reviste el Seguro Popular (Flamand y Moreno, 2015), que fue creado apenas a inicios del presente siglo para dar servicios de salud, principalmente a la población que no pertenece a un sistema de seguridad social, por no ser asalariados o simplemente por estar en la informalidad, 
y si bien no es gratuito sus costos son mucho menores a los de la medicina privada. No obstante, lo noble del proyecto, contrasta con el deterioro que han sufrido en las últimas décadas los servicios de salud y protección de las grandes instituciones como el Instituto Mexicano del Seguro Social (IMSS), que protege la salud y la seguridad social de los trabajadores del sector privado y el Instituto para la Seguridad Social al Servicio de los Trabajadores del Estado (ISSSTE).

La consecuencia de esta política de gasto público se tradujo en: a) que el gasto social por mexicano, en términos reales, se redujera a una cuarta parte, al pasar de 2,388 pesos en 1980, a 587 en 1990 y hasta 818.18 pesos exclusivamente para los pobres en el 2006. b) La aparición de enfermedades consideradas de la pobreza y la insalubridad como el cólera, el paludismo, la tuberculosis, la desnutrición severa, el dengue entre otras, que habían sido erradicadas hacía más de 20 años en México, regresaron a fines de la década de 1980 y continuaron en la década de la globalización y en el siglo XXI. c) La baja en la calidad de la educación pública, evidenciada más con el ingreso de México a la OCDE, organización de países desarrollados, en la que aparece con frecuencia colocado en el último lugar en aprovechamiento de acuerdo a la prueba internacional PISA (por sus siglas en inglés, Tello, 2010, p. 298). d) En general, los escasos logros en el desarrollo integral de los mexicanos constatados por organismos como las Naciones Unidas con los estudios comparativos del Índice de Desarrollo Humano (Anand y Sen, 1993), ${ }^{2}$ en los cuales ocupa México lugares por arriba del número 50, ordenados del mejor al peor en el ranking mundial, junto a países de un nivel de ingreso per cápita incluso menor que el nuestro, ${ }^{3}$ lugar que no ha mejorado al final de la primera década del siglo XXI (PNUD, 2010).

\section{El impacto de las crisis en la desigualdad}

¿En qué medida las crisis impactaron la desigualdad y la pobreza de los hogares mexicanos en las últimas décadas del siglo XX y en la primera del siglo actual? ¿Empeoró o mejoró la desigualdad con las crisis? Para contestar la pregunta utilizamos inicialmente una medida muy simple, pero aceptada, el rango, que mide la diferen-

\footnotetext{
${ }^{2}$ El IDH fue elaborado por Anand y Sen (1993) e incorporado en los reportes anuales del Programa de de las Naciones Unidas para el Desarrollo UNDP. Está compuesto por 3 indicadores: esperanza de vida, educación, e ingreso per cápita medido en dólares constantes de EE.UU. en paridad de poder de compra. Está acotado entre cero el peor desarrollo y uno el más alto, Human Development Index: Methodology and measurement, Cambridge Mass., Harvard University.

${ }^{3}$ Para el nivel educativo consúltese al Human development report. Con base al IDH el Programa elabora un reporte en el que se establece un ranking anual. En el Reporte se desgloza a su vez cada uno de los indicadores para ir captando mejor los cambios en el desarrollo humano. Así, en el correspondiente al año 2002 México aparece en el ranking como país de desarrollo medio en el lugar 54, (pp. 149-193) y en último entre los países de la OCDE, lugares que no ha mejorado al final de la primera década del siglo XXI.
} 
cia de veces que participa de la distribución del ingreso el $10 \%$ más rico, respecto al 10\% más pobres, con base en ella, 1984, es el año de la menor diferencia, menos de 20; mientras que en 1994 y 1992 (Camberos, 2012), reconocidos como los años de consolidación del modelo, alcanza los valores más altos 51 y 50 veces más el valor del ingreso del grupo más rico respecto al ingreso del más pobre, nunca observada en las ultimas 5 décadas del siglo XX en México (Camberos, 2011).

En seguida, para precisar los resultados, elaboramos la tabla 2 que contiene varias medidas de la desigualdad reconocidas por varios autores como recomendables (Atkinson, 1970; Atkinson y Bourguignon, 2003; Shorrocks; 1980 y Shorrocks; 1984), los índices de entropía generalizada (GE), cuyos valores positivos captan más claramente los cambios en la parte alta de la distribución, pero no están acotados entre 0 y 1 , ello dificulta su interpretación.

En la segunda columna de la tabla 2, medimos primero los cambios en la desigualdad observados para cada uno de los años, por medio del índice de Gini, el más utilizado en estos casos, tomando como base 100 el año de inicio del período 1984 , que registra un valor $\mathrm{G}=0.511$ (última columna de la tabla 2) considerado como alto, pero que sin embargo, continuó creciendo a lo largo de las dos primeras décadas del período, que como analizamos arriba, registró varias crisis hasta llegar en el 2000 a su mayor nivel $\mathrm{G}=0.586$, año en que la desigualdad había alcanzado el mayor incremento global, más del $14 \%$ respecto al año inicial. No obstante, el año de la máxima desigualdad también depende de la medida que se escoja.

Tabla 2

La desigualdad en México 1977 - 2008*

\begin{tabular}{|c|c|c|c|c|c|c|c|c|}
\hline \multirow[b]{2}{*}{ Años } & \multirow[b]{2}{*}{$\mathrm{A}(0.5)$} & \multicolumn{3}{|c|}{ Entropía (GE) } & \multicolumn{3}{|c|}{ Atkinson } & \multirow{2}{*}{$\frac{\text { Gini }}{(\mathrm{G})}$} \\
\hline & & $\mathrm{GE}(0)$ & GE(1) & GE(2) & $\mathrm{A}(0.5)$ & $\mathrm{A}(1)$ & $\mathrm{A}(2)$ & \\
\hline 1977 & ------- & 1.050 & 0.204 & ------- & ------- & ------ & ------- & 0.518 \\
\hline 1984 & 100.0 & 0.474 & 0.500 & 0.927 & 0.215 & 0.378 & 0.618 & 0.511 \\
\hline 1989 & 118.6 & 0.547 & 0.670 & 3.145 & 0.255 & 0.422 & 0.661 & 0.545 \\
\hline 1992 & 126.5 & 0.596 & 0.700 & 2.382 & 0.272 & 0.449 & 0.697 & 0.566 \\
\hline 1994 & 132.1 & 0.631 & 0.712 & 1.799 & 0.284 & 0.468 & 0.693 & 0.584 \\
\hline 1996 & 121.4 & 0.581 & 0.685 & 2.537 & 0.261 & 0.440 & 0.662 & 0.564 \\
\hline 1998 & 131.6 & 0.630 & 0.710 & 0.71 & 0.283 & 0.468 & 0.708 & 0.580 \\
\hline 2000 & 134.8 & 0.633 & 0.755 & 2.367 & 0.290 & 0.470 & 0.693 & 0.586 \\
\hline 2002 & 112.1 & 0.526 & 0.580 & 1.161 & 0.241 & 0.409 & 0.628 & 0.540 \\
\hline 2005 & ----- & ----- & ----- & ---- & ----- & ----- & ---- & 0.500 \\
\hline 2006 & ---- & ---- & ----- & ---- & ---- & ----- & --- & 0.510 \\
\hline 2008 & ----- & ---- & ---- & ---- & ----- & ----- & ---- & 0.506 \\
\hline
\end{tabular}

Fuente: Estimaciones propias con base a INEGI, ENIGH 1984 - 2002 y Programas STATA 9 adecuado por Jenkins, S., abril del 2001, excepto para 1977, que fueron tomadas de Hernández y Velázquez, 2003, cuadro 7, p.79. Para los años 2000 y 2008, Coneval (2009); 2005 y 2006, Tello C. (2010), p. 274. 
$\mathrm{Al}$ respecto, si nos guiáramos por el valor del índice de entropía generalizada GE (2) (Shorrocks, 1980 y Shorrocks, 1984)-también podemos mostrar gráficamente el mayor nivel de desigualdad en la figura 1 curva punteada continua-, el punto más alto de la desigualdad es alcanzado en el año de 1989; en tanto que, medido con el índice A (2), resultó 1998, muy cercano el de 1992 y con el coeficiente de Gini G resultó el año 2000, casi igual al de 1994. Esto implica que no podemos deducir completamente cual resultó el peor año de la desigualdad.

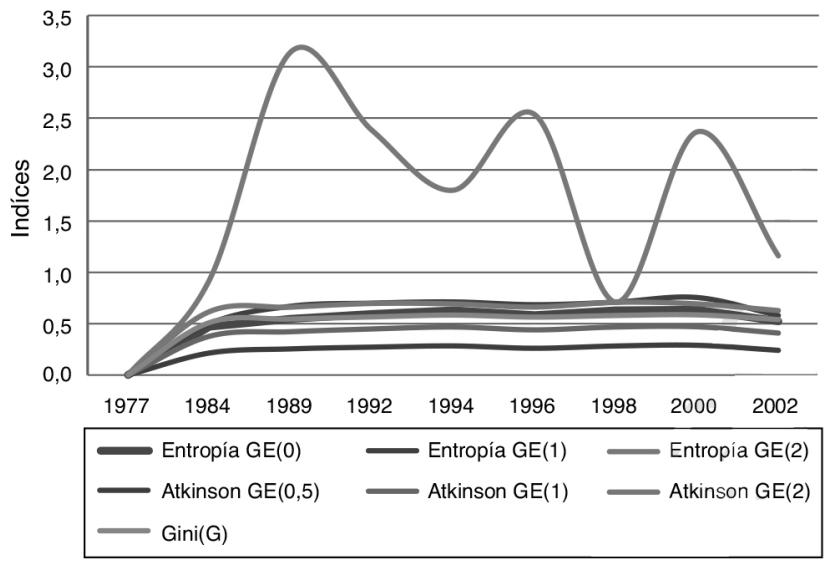

Figura 1. México. Cambios en la desigualdad, 1977 - 2002.

Fuente: Estimaciones propias en base a las ENIGH, 1984 - 2002.

La diferencia de resultados en la medición de la desigualdad tiene que ver con en el grado de sensibilidad que representan las medidas a las transferencias del ingreso, de ahí la importancia de utilizar diferentes medidas. Así, podemos deducir que en los años de 1989 y 2000 el índice GE, (2) indica que hubo transferencias muy fuertes hacia el grupo de más altos ingresos provenientes de los restantes. Estos como efecto de las políticas de apertura, de ajuste y la inflación.

En el caso del índice de Atkinson (2), que es más sensible a las transferencias en la parte baja de la distribución, muestra que en los años de 1992 y 1998 los grupos de bajos ingresos sufrieron un proceso de transferencia inverso al planteado por el principio de Pigou (1916, en Schumpeter, 1973) Dalton (1920), por lo que su ingreso se deterioró aún más, seguramente como producto de los pactos que significaron la contención salarial, la elevada informalidad que alcanzó el mercado laboral en esos años y una mayor libertad en la fijación de precios para los empresarios. El resultado en ambos casos de transferencias es el aumento en la desigualdad. 
Por último, el $\mathrm{G}$ nos dice solamente que la desigualdad alcanzó los niveles mayores en los años de 1994 y el 2000, como producto de la mayor dispersión del ingreso entre todos los grupos. Lo que se puede afirmar es que durante la etapa de desarrollo de México, en contraste con el modelo de desarrollo compartido, que la precedió (1970-1982), la desigualdad siempre ha sido más alta en las 2 últimas décadas, por la que esta se convierte en una característica del neoliberalismo, una de sus debilidades y fuente de las mayores críticas.

El efecto de las crisis en la pobreza 2006-2008 y el impacto de oportunidades en la reducción de la pobreza

Con ser preocupante el efecto negativo de las crisis en la desigualdad, lo es más el que produce en el nivel de bienestar, en tanto que al aumentar el desempleo y reducir el poder de compra de la masa asalariada los pone en riesgo de reducir su bienestar a niveles inaceptables, al grado de no conseguir con el ingreso monetario, producto de su esfuerzo, el mínimo de bienestar social recomendable (World Bank, 2005; UNPD, 2002), por debajo del cual la población se encuentra en pobreza, principalmente en la pobreza extrema o alimentaria, toda vez que ello significa que el ingreso de esa población es insuficiente para adquirir los alimentos que contienen los mínimos requerimientos nutricionales, que les_proporcionan cuando menos la energía suficiente y las proteínas para el desarrollo de las capacidades individuales y los funcionamientos sociales (Nussbaum y Sen, 1996) como el trabajo, el estudio, las relaciones sociales en general.

Por lo tanto, la siguiente tarea es mostrar el impacto de las crisis en la pobreza de México. Nos concentramos en la crisis más reciente y compararemos la situación existente antes de la crisis y los cambios registrados posterior a ella. Para ello, utilizamos el método Lp (Sen, 1976; Sen, 1996) para medir la pobreza, y las bases de datos de las Encuestas de Ingresos y gastos de los Hogares (ENIGH) de México (INEGI, 2006 e INEGI, 2008). Los resultados se contrastan con las estimaciones oficiales y para medir el impacto de Oportunidades en la reducción de la pobreza utilizamos la técnica de microsimulación (Bourguignon, 2006; Corak et al. 2005).

\section{El aumento de la pobreza en México 2006-2008}

En el año 2008, la recesión económica global lanzó a millones de personas al desempleo (ILO, 2009) despojándoles de su fuente de ingresos, lo que en el mundo y también en México significó un mayor riesgo de empobrecimiento para la población, aunque no sólo a causa del desempleo (INEGI, 2009), también por el incremento en los precios de los alimentos (Valero-Gil y Valero, 2008). Por ello, 
para contrarrestar los efectos de la recesión a partir del 2008 el programa Oportunidades, iniciado en el 2002 (Sedesol, 2003), incluyó también el componente Vivir Mejor $^{4}$, que consiste en 2 transferencias más: un apoyo monetario en virtud al alza en los precios de los alimentos, y otro para las familias beneficiarias con hijos de 0 a 9 años (Sedesol, 2007), montos que son incluidos como fuentes de ingreso de los hogares en las ENIGH (INEGI, 2008).

Para sintetizar mejor los resultados elaboramos la tabla 3 en la que se muestran los cambios ocurridos en los niveles de pobreza con la crisis. Así, de no haberse aplicado el programa Oportunidades (columnas $2^{\mathrm{a}}$ y $3^{\mathrm{a}}$ ) los porcentajes de hogares pobres en México, cualquiera sea el tipo de pobreza en el periodo 2006-2008, hubieran aumentado. La pobreza alimentaria hubiera aumentado 3.5 puntos porcentuales, lo cual significaría que los hogares que padecían este tipo de pobreza se habrían incrementado en un $25.1 \%$ del 2006 al 2008; mientras que, la pobreza de capacidades podría haberse incrementado 3.8 puntos porcentuales, lo que implicaría que los hogares en pobreza de capacidades se incrementarían en $19.7 \%$. De igual manera, se hubiera observado un aumento de 3.7 puntos porcentuales respecto a la pobreza patrimonial, es decir, los hogares en este tipo de pobreza se hubieran incrementado un $9.5 \%$ para el 2008.

Pero ¿qué ocurrió con la aplicación de Oportunidades? Al respecto en un estudio para Brasil del impacto del programa Bolsa escola, que realiza transferencia monetarias, como Oportunidades, los autores (Bourguignon et al., 2003) encontraron bajo nivel de impacto en la reducción de la pobreza. ¿Impidió el crecimiento de la pobreza? ¿Contrarrestó el impacto de la crisis? Para responder a los cuestionamientos regresemos a la tabla 3 (columnas $4^{\mathrm{a}}$ y $5^{\mathrm{a}}$ ). En la misma se observa un incremento en los porcentajes de hogares según tipo de pobreza una vez que se aplica el Programa. La pobreza alimentaria aumentó 2.8 puntos porcentuales, lo que significa que los hogares que padecían este tipo de pobreza se incrementaron en un $22.3 \%$ para el 2008; mientras que, la pobreza de capacidades, aumentó en 3.5 puntos porcentuales, lo cual implicó un incremento de $19.3 \%$ en los hogares que vivían este tipo de pobreza de 2006 a 2008. La pobreza de patrimonio aumentó 3.6 puntos porcentuales, por lo que los hogares en tal condición de pobreza se incrementaron en $9.3 \%$ para el 2008.

\footnotetext{
${ }^{4}$ Las reglas de operación de Oportunidades definían en un inicio solo 3 componentes: nutrición, salud y educación, pero esto sufre modificaciones en el transcurso del tiempo y en el 2006 se incorpora un apoyo monetario por cada adulto mayor en el hogar beneficiario, en tanto que para el 2007 se considera también el componente energético; véase www.sedesol.gob.mx
} 
Tabla 3

México. Índices de pobreza alimentaria, capacidades y patrimonial FGT (0), 2006 - 2008.

\begin{tabular}{|c|c|c|c|c|c|c|c|c|}
\hline \multirow[t]{2}{*}{ Tipo de pobreza } & \multicolumn{2}{|c|}{ Sin oportunidades } & \multicolumn{2}{|c|}{ Con oportunidades } & \multicolumn{2}{|c|}{ Con monto máximo ${ }^{\mathrm{d}}$} & \multicolumn{2}{|c|}{ Coneval $^{\mathrm{e}}$} \\
\hline & Año 2006 & Año 2008 & Año 2006 & Año 2008 & Año 2006 & Año 2008 & Año 2006 & Año 2008 \\
\hline Alimentaria $^{a}$ & $\begin{array}{l}13.63 \\
{[0.003]}\end{array}$ & $\begin{array}{l}17.05 \\
{[0.004]}\end{array}$ & $\begin{array}{l}12.76 \\
{[0.004]}\end{array}$ & $\begin{array}{l}15.61 \\
{[0.004]}\end{array}$ & $\begin{array}{c}2.69 \\
{[0.001]}\end{array}$ & $\begin{array}{c}5.42 \\
{[0.002]}\end{array}$ & $\begin{array}{l}10.60 \\
{[0.004]}\end{array}$ & $\begin{array}{l}14.30 \\
{[0.008]}\end{array}$ \\
\hline Capacidades $^{\mathrm{b}}$ & $\begin{array}{l}19.35 \\
{[0.004]}\end{array}$ & $\begin{array}{l}23.16 \\
{[0.005]}\end{array}$ & $\begin{array}{l}18.48 \\
{[0.004]}\end{array}$ & $\begin{array}{l}22.05 \\
{[0.005]}\end{array}$ & $\begin{array}{c}6.21 \\
{[0.002]}\end{array}$ & $\begin{array}{c}9.52 \\
{[0.003]}\end{array}$ & $\begin{array}{l}16.10 \\
{[0.006]}\end{array}$ & $\begin{array}{l}20.10 \\
{[0.009]}\end{array}$ \\
\hline Patrimonial $^{\mathrm{c}}$ & $\begin{array}{l}38.69 \\
{[0.005]}\end{array}$ & $\begin{array}{l}42.37 \\
{[0.006]}\end{array}$ & $\begin{array}{l}38.36 \\
{[0.005]}\end{array}$ & $\begin{array}{l}41.95 \\
{[0.006]}\end{array}$ & $\begin{array}{l}24.30 \\
{[0.004]}\end{array}$ & $\begin{array}{l}27.38 \\
{[0.005]}\end{array}$ & $\begin{array}{l}35.50 \\
{[0.006]}\end{array}$ & $\begin{array}{l}40.20 \\
{[0.012]}\end{array}$ \\
\hline
\end{tabular}

*Variación porcentual en el periodo 2006-2008:

\begin{tabular}{|c|c|c|c|c|}
\hline Alimentaria & 25.1 & 22.3 & 101.5 & 34.9 \\
\hline Capacidades & 19.7 & 19.3 & 53.3 & 24.8 \\
\hline Patrimonial & 9.5 & 9.3 & 12.7 & 13.2 \\
\hline
\end{tabular}

*Impacto respecto a la situación sin oportunidades

\begin{tabular}{llll}
\hline & Con Oportunidades & Con monto máximo & Coneval \\
\hline Alimentaria & -2.73 & 76.4 & 9.9 \\
Capacidades & -0.34 & 33.7 & 5.2 \\
Patrimonial & -0.17 & 3.2 & 3.7 \\
\hline
\end{tabular}

Las estimaciones se hacen con las nuevas bases de datos de la ENIGH que incorporan la conciliación demográfica realizada por el INEGI y el CONAPO.

La cifra que aparece entre corchetes es el dato del error estándar.

Fuente: Cálculos propios en base a la metodología del CTMP, el método de Líneas de Pobreza, Micro-simulación Estática y las ENIGHs 2006 y 2008.

a) La pobreza alimentaria se refiere a los hogares cuyo ingreso percápita es menor al necesario para cubrir las necesidades de alimentación correspondientes a los requerimientos establecidos en la canasta alimentaria INEGI-CEPAL.

b) Se refiere a los hogares cuyo ingreso per capita es menor al necesario para cubrir el patrón de consumo básico de alimentación, salud y educación.

c) Se refiere a los hogares cuyo ingreso per capita es menor al necesario para cubrir el patrón de consumo básico de alimentación, vestido y calzado, vivienda, alud, transporte público y educación.

d) Según el programa Oportunidades en el año 2006 el monto máximo mensual que se podría asignar a una familia eran $\$ 1,855.00$ pesos (1.31 SMM), es decir $\$ 475.64$ por persona mensual; mientras que, en el 2008 , este monto eran $\$ 2,220.00$ pesos (1.46 S.M.), lo que significaba $\$ 569.23$ pesos por persona al mes.

Datos tomados de las estimaciones hechas por el CONEVAL

Como puede desprenderse de los resultados mostrados, el programa Oportunidades no logró impedir sustancialmente el empobrecimiento de los hogares mexicanos; sin embargo, cabe decir que si ayudó, si bien es cierto marginalmente, a una mayor reducción de la pobreza alimentaria, no así en la de capacidades y patrimonial, en las cuales su impacto fue de casi 0 . 


\section{El impacto de Oportunidades}

Pese al aumento observado en el porcentaje de hogares según tipo de pobreza $(22.3 \%, 19.3 \%$ y $9.3 \%)$, en el contexto de la recesión económica internacional y el aumento en precios de los alimentos, el programa Oportunidades muestra cierto impacto al amortiguar de manera marginal la incidencia en los 3 tipos de pobreza. Así, se observa que la aplicación de Oportunidades si bien no contrarrestó el incremento en los niveles de pobreza, al menos evitó que la proporción de hogares mexicanos en pobreza alimentaria se incrementara en $2.73 \%$, y las familias en pobreza de capacidades en $0.34 \%$ durante el periodo 2006-2008. Igualmente, las transferencias monetarias de Oportunidades evitaron que los hogares en pobreza de patrimonio se incrementaran en 0.17\% durante el periodo 2006-2008.

\section{El efecto de una política de monto máximo}

En caso de que el programa Oportunidades se hubiera aplicado de manera focalizada, pero en lugar de dosificar los apoyos transfiriera el monto máximo a todos los hogares identificados como pobres, es decir al universo de hogares en pobreza durante el periodo 2002-2006 y que ésta modalidad de intervención hubiera tenido continuidad en el 2006-2008, los hogares que padecían los tres tipos de pobreza habrían presentado un inevitable incremento en el contexto de la recesión económica para el 2008; sin embargo, los niveles de pobreza hubieran sido mucho más bajos a los que en realidad se presentan con la política social actual en el 2008.

Claro, todo ello bajo el supuesto de que la transferencia del monto máximo se hace de manera eficiente, lo que a su vez implicaría que se minimizan lo errores de inclusión y exclusión en el ejercicio de focalización de la política social. De tal manera, ésta modalidad de intervención podría haber puesto al país en la senda de la principal meta del milenio para el 2015: la erradicación de la pobreza extrema y el hambre ${ }^{5}$, incluso el porcentaje de hogares en pobreza de capacidades se hubiera reducido más de la mitad respecto a los niveles del 2002, ya que como se aprecia en la misma tabla 3 (columnas $6^{\mathrm{a}}$ y $7^{\mathrm{a}}$ ), solo el $5.4 \%$ de los hogares mexicanos viviría en pobreza alimentaria, el $9.5 \%$ en pobreza de capacidades y el $27.4 \%$ en pobreza patrimonial con esta política social para el 2008, a pesar del incremento en el costo de los alimentos y de la crisis financiera global .

\footnotetext{
${ }_{5}^{5}$ Véase al respecto www.un.org
} 


\section{Las estimaciones oficiales}

De acuerdo a las estimaciones del Coneval (tabla 3, columna 9a), también hubo un incremento en los porcentajes de hogares por tipo de pobreza en el país durante el periodo 2006-2008 . Los hogares que vivían en pobreza alimentaria se incrementaron en $34.9 \%$, los que estaban en pobreza de capacidades tuvieron un incremento del $24.8 \%$, mientras que los hogares en pobreza patrimonial se incrementaron en $13.2 \%$ para el 2008; sin embargo, al comparar la variación porcentual con la situación sin Oportunidades se puede ver que con las estimaciones oficiales y pese a las transferencias del programa Oportunidades, los hogares en pobreza alimentaria aumentaron en 9.9\%, los hogares en pobreza de capacidades en 5.2\% y las familias en pobreza patrimonial en 3.7\% durante el periodo 2006-2008.

Dos explicaciones del limitado impacto de Oportunidades en la reducción de la pobreza

¿A qué se debe el reducido impacto de oportunidades? Dos de las explicaciones más consistentes son: a) La insuficiencia de recursos que se dedican al programa; y b) los errores de focalización en la aplicación del mismo. Respecto al primer punto, tomamos como referencia el año 2006 cuando el monto total asignado al programa Oportunidades ascendió a casi 33,000 millones de pesos ( $0.40 \%$ del PIB de México).

Para evaluar si los recursos destinados son suficientes compárense con aquéllos que hipotéticamente deberían destinarse al combate a la pobreza, recursos que son estimados de la siguiente manera: $C P=(q)(I)(Z)$, donde $C P$ son los costos económicos para que los hogares puedan superar la condición de pobreza; $q$, es la cantidad de hogares en pobreza, $I$ es la brecha de pobreza estandarizada y $Z$ la línea de pobreza según tipo de pobreza. De acuerdo a esta forma de estimación, la magnitud de los recursos requeridos para el combate a la pobreza en el país ascendían a 168,142 millones de pesos -equivalentes al 2.05\% del PIB nacional-, los que resultan ser 5 veces mayores a los que la Sedesol asigna al programa Oportunidades, por lo puede resultar que el programa sea excluyente dada la insuficiencia de recursos.

En lo que se refiere al problema de la focalización, los autores Cornia y Stewart (2015) advierten sobre la existencia de 2 errores en la focalización de la política

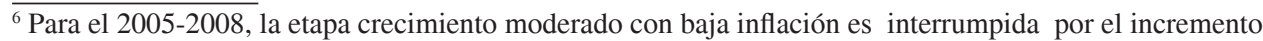
en los precios de los alimentos, la elevación de los precios internacionales del petróleo y el inicio de la crisis económica mundial, por lo que la actividad económica se contrajo más de $6 \%$ aunque la inflación anual se mantuvo debajo de 4 puntos porcentuales para el 2009 (Coneval, 2011[p. 12, tabla 1.1]), lo que sin duda explica la tendencia creciente de los niveles de pobreza en el segundo quinquenio de la década en el país y las regiones.
} 
social: el error de omisión o exclusión de los pobres [error de tipo I] y el error de inclusión de los no pobres [error de tipo II], los cuales se reconoce existen en la implementación de la política social en el país (Boltvinik, 2004). De acuerdo con Pérez et al. 2010, el error de exclusión es la proporción de hogares pobres no-beneficiarios respecto al total de la población pobre: representa la sub-cobertura; mientras que el error de inclusión representa la filtración, que es el número de hogares beneficiarios no pobres dividido por la población total de beneficiarios. La tasa de inclusión en la focalización es la relación de los hogares pobres beneficiarios respecto al total de hogares pobres, y la tasa de exclusión es la relación de los hogares no beneficiarios que no son pobres respecto al total de hogares que no están en pobreza.

En términos más específicos, el error de inclusión comprende el porcentaje del total de hogares beneficiarios que no son pobres; mientras que, el error de exclusión es el porcentaje de hogares pobres que no son cubiertos por el programa Oportunidades; por lo tanto, para un mejor desempeño en la focalización o selección de hogares beneficiarios del programa se deben de minimizar estos errores, lo cual no sólo depende de la línea de pobreza y de la forma en que se mide ésta.

Tabla 4

México. Errores en la focalización del Programa Oportunidades 2002, 2006 y 2008.

\begin{tabular}{lrrrr}
\hline Año & $\begin{array}{c}\text { Error de Exclusión: } \\
\text { (Sub-cobertura) }\end{array}$ & $\begin{array}{c}\text { Error de Inclusión: } \\
\text { (Filtración) }\end{array}$ & Tasa de Inclusión: & Tasa de Exclusión: \\
\hline & & & & \\
2002 & 75.3 & 8.6 & 24.7 & 98.1 \\
2006 & 78.5 & 40.7 & 21.5 & 91.3 \\
2008 & 68.8 & 16.9 & 31.2 & 95.4 \\
Variación \% & -8.6 & 95.6 & 26.3 & -2.7 \\
& & & & \\
\hline
\end{tabular}

Fuente: Estimaciones propias con base en las ENIGH 2002, 2006 y 2008.

Para mostrar que tan real y persistente ha sido este problema, realizamos un análisis de la década que incluye los años previos a la crisis reciente y el de inicios de la misma por medio de la tabla 4, en el que se muestra al comparar el ejercicio de focalización del programa Oportunidades en los años 2002, 2006 y 2008, tasas de exclusión por encima del $95 \%$ las cuales son muy altas dada la escala del programa y, aunque la tasa de exclusión disminuyó al 91\% en el 2006, se observa que hubo un deterioro en términos del error de exclusión o porcentaje de sub-cobertura y la tasa de inclusión en este mismo año, para luego mejorar de manera importante en el 2008. 
De esta manera, la proporción hogares pobres no beneficiarios se incrementó a $78.5 \%$ para el 2006 y luego disminuyó a $68.8 \%$ en el 2008, lo cual inicialmente se reflejó en una disminución de la tasa de inclusión (21.5\%) y luego en un incremento hasta del $31.2 \%$ en el 2008 . Por otra parte, se hace evidente un deterioro sustancial respecto al error de inclusión en la implementación de Oportunidades: el $40.7 \%$ de todos los hogares beneficiarios no eran pobres en el año 2006, ésta cifra disminuyó a $16.9 \%$ para el 2008 , pero prácticamente representa el doble respecto al error de inclusión del 2002.

Los programas de transferencias monetarias focalizadas se enfrentan a la disyuntiva entre la eficacia (llegar a los pobres) y mejorar la eficiencia (la eliminación de los no pobres). Si un programa concede menos importancia a los errores de inclusión (es decir, en beneficio de los no pobres), tendrá que gastar más dinero para tener el mismo impacto sobre la pobreza como un programa más eficiente. Por el contrario, si un programa concede menos importancia al hecho de llegar a la mayor cantidad de hogares pobres posible, su impacto sobre la pobreza global podrá ser inferior, incluso si es capaz de mejorar su eficiencia (Perez et al, 2010).

En este sentido, a nivel país el error de exclusión (68.8\%) sigue siendo casi igual que el de 2002, lo cual significa que en realidad se atiende a 31 de cada 100 pobres, por ello la tasa de inclusión (31\%) sigue siendo baja en el 2008; mientras que el error de inclusión (16.9\%) prácticamente se duplicó, lo cual influye en el exiguo impacto de Oportunidades en la reducción de la pobreza en México.

En resumen, en el periodo analizado no se observa una mejora sustancial en la eficacia del programa (cobertura de los pobres) como tampoco en la eficiencia (eliminación de los no pobres), lo que se refleja en un alto error de exclusión o subcobertura de hogares en pobreza y también en un alto error de inclusión o filtración de hogares no pobres en la focalización del programa Oportunidades en el periodo 2002-2008, lo que constituye, de suyo, el error de focalización, un factor que impide al programa operar con la eficiencia y eficacia necesaria para reducir más rápido la pobreza; por lo tanto, en un escenario futuro debe atenderse este problema paralelamente al del aumento de los recursos destinados al Programa, y con ello incrementar las transferencias monetarias a los hogares pobres de México, 2 factores que contribuirán al cumplimiento de las metas del milenio de reducir la pobreza en el 2015 a la mitad de la existente en el 2000 (United Nations, 2000).

La crisis, el crecimiento económico, la desigualdad y su impacto en la pobreza

El crecimiento económico es un mecanismo que puede ser la base para reducir la pobreza; pero la desigualdad podría aumentar la pobreza. Bajo este escenario, la 
crisis reduce el crecimiento a cero y deja prácticamente a la desigualdad el papel de actuar sobre la pobreza. Explicamos a continuación cómo se da la relación y al final mostramos la aplicación para México de cómo la desigualdad pudo haber impactado a la pobreza.

La relación entre pobreza $(\mathrm{P})$, crecimiento económico $(\mathrm{G})$ y desigualdad (I) puede establecerse de manera sencilla (Fuentes, 2005) por medio de una función, que representa la condición necesaria:

$$
\mathrm{P}=(\mathrm{G}, \mathrm{I}), \text { especificada como } \mathrm{P} / \mathrm{G}<0 ; \mathrm{P} / \mathrm{I}>0
$$

De (1) se desprende fácilmente que la pobreza disminuirá con el crecimiento económico manteniéndose constante la desigualdad (I); sin embargo, de los estudios del desarrollo basados en Kuznets (1955) y las experiencias de América Latina hemos aprendido que $I$ no siempre permanece constante en el proceso de desarrollo; por lo tanto su efecto puede ser diverso: a) La pobreza se reduce si al crecer la economía (G) no cambia $I$, siempre y cuando el valor de $I$ al inicio del proceso de desarrollo sea bajo; b) La pobreza disminuye más rápido si a la par de $G$ baja la desigualdad; c) la pobreza puede aumentar, a pesar de $G$, si la sensibilida del cambio de $\mathrm{P}$ es mayor a $I$ que al crecimiento económico, de tal suerte que inhiba el efecto de $G$.

Luego tenemos dos casos extremos: d) la pobreza puede reducirse aunque no haya crecimiento económico o este fuera negativo, si tras una reducción generalizada del ingreso, como ocurre con las crisis, se diera una redistribución desde los grupos más ricos a favor de los pobres y de los grupos de ingreso medios bajos que los mantuviera por encima de la línea de pobreza; e) y el caso contrario, la pobreza pudiera crecer aunque se redujera la desigualdad, pero el ingreso sufriera una caída drástica.

Por lo tanto, dada la complejidad de la relación proveniente de la desigualdad, deberá buscarse su optimización combinando los 3 elementos, tal y como lo contemplan las políticas conocidas como pro-poor (Kakwani y Son, 2008), que permiten maximizar la combinación de los 3 componentes para constituir la condición suficiente:

$$
\max : d P / d t<d(G, I) / d t
$$

Esto es, (2) significa que la mezcla de políticas no solamente busca la reducción de la pobreza, sino su mayor disminución en un período de tiempo, por ejemplo 2000-2015, en el que se planteó la meta del milenio. 


\section{El impacto de la desigualdad en la pobreza}

Una estimación gruesa de cómo la desigualdad ha propiciado el aumento en la pobreza, basados en (1) y (2), la podemos obtener de la tabla 5, bajo la hipótesis de que el valor de la desigualdad, medido por el coeficiente de Gini $(G)$, representa la proporción con la que contribuye al nivel de la pobreza, bajo el razonamiento de que si $\mathrm{G}=0$ el solo crecimiento económico abatiría la pobreza; sin embargo, en la medida que $\mathrm{G}$ es diferente de 0 , su contribución es creciente a medida que se acerca a 1; es decir, por si misma, la desigualdad duplica la pobreza cuando adquiere valores $\mathrm{G}$ cercanos al 0.5 .

Tabla 5

Contribución de la desigualdad a la pobreza.

\begin{tabular}{llll}
\hline Años & No pobres & Desigualdad Gini $(\mathrm{G})$ & $\begin{array}{l}\text { Contribución de la } \\
\text { desigualdad a la pobreza }\end{array}$ \\
\hline 1984 & $30,643.33$ & 0.511 & $1,56,58,740$ \\
1989 & $39,520.78$ & 0.545 & $2,15,38,827$ \\
1992 & $4,61,38,837$ & 0.566 & $2,61,14,581$ \\
1994 & $4,70,45,221$ & 0.584 & $2,74,74,409$ \\
1996 & $6,39,67,416$ & 0.564 & $3,60,07,622$ \\
1998 & $6,06,71,333$ & 0.58 & $3,51,89,373$ \\
2000 & $5,27,00,549$ & 0.586 & $3,08,82,521$ \\
2002 & $5,04,06,024$ & 0.54 & $2,72,19,252$ \\
2004 & $4,86,25,044$ & NA & NA \\
2005 & $4,88,95,535$ & 0.5 & $2,44,77,104$ \\
2006 & $4,46,77,884$ & 0.51 & $2,27,85,720$ \\
2008 & $5,05,50,829$ & 0.51 & $2,58,50,000$ \\
2010 & $5,77,07,660$ & ------ & ------ \\
\hline
\end{tabular}

Fuente: n.o de pobres 1984-1989, CEPAL-INEGI (1993); propia: 2005 y 2010, Coneval (2009 y 2011); 2008, World para 1992-2006, Coneval (2009); Gini 1984-2002 estimación Bank, 2006 y Tello (2010). p. 274.

De la tabla 5 se desprende claramente cómo en la medida que se incrementó la desigualdad entre 1984 y el 2000 la pobreza alcanzó altos niveles que superaron los 50 millones. Si bien es necesario reconocer que la falta de crecimiento entre 1984 y 1996 contribuyó también a esos niveles. Lo que debe quedar claro es que el efecto negativo de la desigualdad en el bienestar, señalado páginas arriba, particularmente cuando producto de la crisis no hay crecimiento económico, se constituye en un factor que contribuye, a su vez, al empobrecimiento de la población y que por lo tanto debe ser objeto de la política social (Bracamontes et al., 2012), implementar medidas para su reducción de manera sistemática muy por debajo de $\mathrm{G}=0.5$, consolidando los programas como Oportunidades. 


\section{Conclusiones}

A lo largo de este trabajo se hace por demás evidente el impacto negativo que han tenido las crisis de las últimas décadas en la pérdida de empleos formales y la caída del salario real; pero también se ha contabilizado el aumento de los pobres hasta rebasar los 50 millones de mexicanos; así como el aumento de la desigualdad, medida con el coeficiente de Gini, mayor al 0.5, siendo de los más altos en América Latina y de sus socios de la OCDE.

¿Qué hacer para reducir la desigualdad y la pobreza de México? Se requiere de reformas económicas más de fondo que afecten la demanda laboral, para sentar las bases e incrementar las oportunidades de empleos mejor remunerados, que beneficien a los individuos de los grupos bajos y medios e impulsen la movilidad de la fuerza de trabajo, lo cual reduciría las diferencias de ingreso al interior de los grupos y entre ellos, de tal suerte que llevaría a la reducción de la desigualdad, pero no como ocurrió en México con las crisis y recesiones de 1995, 2002 y 2008-2009, sino generando mayor riqueza y haciendo participar más a los grupos de bajos y medianos ingreso.

Un camino que se ha utilizado en otros países para lograr las reformas económicas que coadyuven a reducir la desigualdad y la pobreza, como ocurrió en EE.UU. en las primeras décadas del siglo pasado y en España en las últimas décadas, es combatiendo los monopolios, sean privados o públicos, porque inhiben la libre competencia y las iniciativas individuales. También se debería intensificar el proceso de calificación y certificación de la mano de obra, ello le daría al trabajador mexicano un elemento para negociar un salario más alto.

Cualquier propuesta quedaría trunca sin la reforma tributaria y redistributiva. Esta implicaría revisar el sistema impositivo: ingresos, subsidios y transferencias a las empresas, hogares e individuos. Como parte de ella, debería considerarse el gravamen no solamente del ingreso, sino de la riqueza y del capital financiero, fuente especulativa de concentración. Ello contribuiría a reducir el grave problema del ocultamiento y, de paso, a incentivar la creación de fundaciones u organizaciones de apoyo a las personas con capacidad, talento e ingenio, que los impulse a convertirse en emprendedores, innovadores, en lugar de informales, lo que llevaría a la redistribución del ingreso y la riqueza y a la disminución de la desigualdad.

Tal vez la consecuencia más grave de las crisis ha sido el empobrecimiento de una gran cantidad de mexicanos que ya rebasa los 50 millones, y ante las evidencias encontradas en este estudio de que en gran parte la insuficiencia de los recursos asignados a la política social de combate a la pobreza explica en buena medida el exiguo impacto del programa Oportunidades en la reducción de los hogares en 
situación de pobreza en el país, se debe incrementar el monto de recursos económicos para la puesta en práctica de esta importante iniciativa de política social, que eleve las transferencias para beneficiar a más hogares pobres producto de la crisis más reciente.

Aunado a lo anterior se presenta la necesidad de hacer una revisión y un importante replanteamiento de la focalización en la política social actual, en términos de la forma en que se ha venido concibiendo y aplicando hasta hoy. En general, además de que los recursos de la política social vigente resultan insuficientes en relación a los costos económicos de combate a la pobreza, actualmente la asignación de las transferencias monetarias no sólo se hace de manera focalizada, sino que también estos apoyos monetarios se otorgan de manera dosificada en cada uno de los hogares. Por lo tanto, ante la imperiosa necesidad de mayor financiamiento, también se requiere una nueva forma de intervención de la política social, la cual propicie un mayor impacto generando la inserción de los pobres hacia una mejor calidad de vida.

Si en el corto plazo en verdad interesa una política social que sea más efectiva en la lucha contra la pobreza en México, se deben reducir al mínimo los errores de focalización tipo I y II, lo que garantizaría el uso más eficiente de los recursos, para luego explorar nuevas formas de intervención y una de ellas pudiera ser la política social focalizada de monto máximo, cuyo impacto como se ha visto sería indiscutible. El problema estribaría en su financiamiento, pues hubiera significado una proporción de recursos por el orden del $2.05 \%$ del PIB nacional, cantidad que resulta muy superior al $0.40 \%$ asignado al programa Oportunidades en el 2006.

\section{Referencias}

Alba, F. (1993). El mercado de trabajo: cambios en el modelo de absorción de la fuerza laboral. México auge, crisis y ajuste. En: C. Bazdrech, N. Bucay, S. Loaeza y N. Lustig, comps. México: El Trimestre Económico, FCE Lecturas73:179-200.

Aspe, P. (1993). El camino mexicano hacia la transformación económica. México: FCE.

Anand, S. y Sen, A. (1993). Human development index: Methodology and measurement. Cambridge: Harvard University Press.

Atkinson, A.B. y F. Bourguignon (2003). Handbook of income inequality. North-Holland: Elsevier, Amsterdan.

Atkinson, A. (1970). On the measurment of inequality. Journal of Economic Theory, 2, 244-263.

BBVA-BANCOMER (2001). Reporte regional. México: Bancomer

Blankfeld, K. (2011). Top ten billionaires money gainers. Forbes. Disponible en:.http://blogs.forbes. com/kerenblankfeld/2011/03/11/top-ten-billionaires.money-gainers/ (Consultado el 14 de septiembre 2011). 
Boltvinik, J. (2004). In J. Boltvinik y A. Damián (Eds.), Políticas focalizadas de combate a la pobreza en México. El Progresa/Oportunidades. La pobreza en méxico y el mundo, realidades y desafíos (pp. 315-347). México: Siglo XXI y Gobierno de Tamaulipas.

Boltvinik, J. (1994). La estratificación social de la pobreza en México. México: INEGI, COLMEX, IIS-UNAM.

Bourguignon, F. y Spadaro, A. (2006). Microsimulation as a tool for evaluating redistribution policies. Working Papers 20. ECINEQ. Paris, Society for the Study of Economic Inequality.

Bourguignon, F., Ferreira, H. G. y Leite, F. (2003). Conditional cash transfers schooling and child labor: Micro-simulating

Brasil's Bolsa Escola Program. World Bank Economic Review, 17, 229-254.

Bracamontes, J., Camberos, M. y Huesca, L. (2012). Una evaluación de política pública: el impacto de oportunidades en México y sus diferentes regiones. En M. Á. Mascott y G. Meixueiro (Eds.), Premio Nacional de Investigación Social y de Opinión Pública 2011. (pp. 23-63). México: CESOP.

Bracamontes, J., Ledezma, D. y Camberos, M. (2011). El efecto de Oportunidades en la pobreza de México y la Región Norte, 2002-2006. Economía Sociedad y Territorio, XI, 41-93.

Bravo, A. L. (1993). La apertura comercial 1983-1988. Contribución al cambio estructural de la economía mexicana. En C. Bazdrech, N. Bucay, S. Loaeza, y N. Lustig (Eds.), México auge, crisis y ajuste (pp. 317-346). México: El Trimestre Económico, FCE Lecturas. 73.

Camberos, M. (2012). Impacto de la desigualdad en el bienestar y la pobreza bajo el neoliberalismo. Recomendaciones para un nuevo modelo. Empleo digno, distribución del ingreso y bienestar. En J. L. Calva (Ed.), Análisis estratégico para el desarrollo (pp. 245-265). México: Juan Pablos Editor.

Camberos, M. y Bracamontes, J. (2011). La crisis económica y el mercado laboral de la frontera Norte de México: ¿Qué política económica implementar para reactivarlo. En B. Vázquez, M. Jurado, y J. L. Castro (Eds.), Procesos económicos, laborales y urbanos en la frontera noreste en el contexto de la apertura económica. (pp. 45-173). Monterrey: Colegio de La Frontera y Universidad de Coahuila.

Camberos, M. y Yáñez, J. (2003). La informalidad de los mercados laborales de Sonora y la frontera norte de México. Región y Sociedad, XV, 35-47.

Camberos, M. (1995). La desigualdad en México y las expectativas con un modelo neoliberal. En J. Calva (Ed.), Distribución del ingreso en México y políticas sociales (pp. 139-158). México: JP editores.

Camberos, M. (1994). El crecimiento y la desigualdad en el largo plazo en México. Análisis Económico XII, 113-141.

Casanueva, C. y Rodríguez, C. (2009). La productividad en la industria manufacturera mexicana. Comercio Exterior, 59, 6-33.

Conapo (2001). Índices de marginación 2000. Ciudad de México: Consejo Nacional de Población.

CIDAC. (2011). Hacerlo mejor. Índice de productividad. México: Centro de Investigación para el Desarrollo.

Coneval (2013). Informe sobre la pobreza multidimensional en México 2012. Disponible en:http:// www.coneval.gob.mx/Medicion/Paginas/Medici\%C3\%B3n/Pobreza\%202012/Pobreza-2012. aspx (Consultado el 27 de agosto de 2013)

Coneval (2009). Metodología para la medición multidimensional de la pobreza en México. Sedesol, México. 
Consejo Nacional de Evaluación de la Política de Desarrollo Social (CONEVAL) (2011). Reporte sobre la pobreza en México. Sedesol, México.

Corak, M., Lietz, C. y Sutherland, H. (2005). The impact of tax and transfer systems on children in the European Union. Working Paper 2005-04. New York: UNICEF Innocenti Research Centre.

Cornia G., y Stewart F. (2015). Two errors of targeting. Disponible en:. http://www-3.unipv.it/iuss/ cds/userfiles/file/Papers/paper cornia 5.pdf. (Consultado el 5 de marzo 2011).

Dalton, H. (1920). Measurement of the inequality of income. The Economic Journal, 348-361.

Dornbusch, R. y Startz, R. (2000). Macroeconomía. México: Mc Graw Hill.

Ferreira, F. H., Messina, J., Rigolini, J., López, C. M, Lugo, A. y Vakis, R. (2013). La movilidad económica y el crecimiento de la clase media en América Latina. Washington D.C.: Banco Mundial.

Flamand L. y Carlos Moreno J. (2015).Seguro popular y federalismo en México: Un análisis de política pública. CIDE. Ciudad de México.

Fuentes R. (2005) Poverty, Pro-Poor Growth and Simulated Inequality Reduction. Human Development Report. New York: UNDP.

Gittli, E. (1990). La dinámica del comercio exterior mexicano. In México en la década de los ochenta. México: UAM-A.

Gil, F. y Ramos, R. (1988). Lecciones desde México. En G. Bruno, R. di Tella, Dornbusch, y S. Fisher (Eds.), Inflación y estabilización. (62.) (pp. 425-457). México: El Trimestre Económico. FCE Lecturas.

Hernández, E. y Velázquez, J. (2003). Globalización. In desigualdad y pobreza. México: UAM-PyV Huesca L.(2005).La distribución salarial del mercados de trabajo en México, un análisis de la informalidad. Tesis Doctoral. España:UAB

ILO (2013) Global Employment Trends 2013: Facts and figures for Latin America \& the Caribbean. Disponible en: http://www.ilo.org/global/research/global-reports/global-employment trends/2013/WCMS 202303/lang-es/index.htm (Consultado el 12 de marzo del 2011).

ILO (2012). World of Work Report. Geneveve: International Labour Organization.

ILO (2011). Statistical update on employment in the informal economy. Disponible en: http://www. ilo.org/wcmsp5/groups/public/dgreports/stat/documents/presentation/wcms 157467.pdf (Consultado el 12 de marzo del 2011).

ILO (2001). World employment: Life at work in the informal economy. Geneve:. International Labour Organization.

ILO(2009). Guide to the new millenium development goals employment indicators: including the Full Set of decent work indicators. Geneve.Intenational Labor Office.Employement sector. ILO, Disponible en:http://www.ilo.org/wcmsp5/groups/public/@ed_em/document/publication/wcms_110511.pdf (Consultado el 15 de febrero de 2009).

INEGI (2014). Portal ocupación y empleo. Disponible en: http://www3.inegi.org.mx/Sistemas/temas/Default.aspx?s=est\&c=25433\&t=1 (Consultado el 08 de octubre del 2014).

INEGI (2013a). Índice de la productividad laboral y del costo unitario de la mano de obra 2012. disponible en: http://www.stps.gob.mx/bp/secciones/conoce/areas atencion/areas atencion/web/ productividad/Aspectos.pdf (Consultado el 28 de julio del 2013).

INEGI (2013b). Población ocupada en el sector informal, 2005-2010, 3.er. Trimestre. México: Instituto Nacional de Estadística Geografía e Informática.

INEGI (2012). Encuesta nacional de ocupación y empleo. México: INEGI.

INEGI (2011). Censos generales de población y vivienda, 2010. México: INEGI.

INEGI (2010). Encuesta nacional de ocupación y empleo. México: INEGI. 
INEGI (2009). Encuesta nacional de ocupación y empleo. México: INEGI.

INEGI (2008). Encuesta nacional de ingresos y gastos de los hogares de México. México: INEGI. INEGI (2007). Encuesta nacional de ocupación empleo. México: INEGI.

INEGI (2006), Encuesta nacional de ingresos y gastos de los hogares de México. México: INEGI.

INEGI (2001). Censos generales de población y vivienda, 2000. México: INEGI.

INEGI (1996). I y II conteo de población y vivienda. México: CONAPO

INEGI (1992). Censos generales de población y vivienda, 1990.México: INEGI.

ITESM (2010). Estimaciones sobre pobreza para el 2010. Monterrey: Centro de Investigación en Economía y Negocios.

Jusidman, C. y Eternod, M. (1993). La participación de la población en la actividad económica de México. México: INEGI, IIS-UNAM.

Kakwani, N. y Son, H. (2008). Poverty Equivalent Growth Rate. Review of Income and Wealth, LIV, 643-655.

Krugman, P. (2012). End this depression now! New York: W.W. Norton \& Company.

Kuznets, S. (1955). Economic growth and income inequality. In American economic review march.

Chicago: American Economic Association.

Levy, S. (1991). La pobreza extrema en México: una propuesta de Política. Estudios económicos VI (1). México: El Colegio de México.

López, G. (2003). Wages and productivity in Mexican manufacturing. Washington: The World Bank.

Disponible en: http://elibrary.worldbank.org/content/workingpaper/10.1596/1813-9450-2964 (Consultado el 28 de julio del 2013).

Lustig, N. (1999). Pobreza y desigualdad: un desafío que perdura, Revista de la CEPAL núm. Extra. Santiago De Chile, CEPAL, 297-313.

Lustig, N. (1993). El efecto social del ajuste. En C. Bazdrech, N. Bucay, S. Loaeza, y N. Lustig (Eds.), México auge,crisis y ajuste. (pp. 201-238). México: El Trimestre Económico.

Nussbaum, M. y Sen, A. (1996). La calidad de vida. México: FCE.

Nafinsa (1990). La economía mexicana en cifras. Ciudad de México.

Nafinsa (1995).La economía mexicana en cifras. Ciudad de México.

OIT. (2009). La crisis mundial del empleo: modalidades y escenarios de mediano plazo; informe sobre el trabajo en el mundo. Génova: Organización Internacional del Trabajo.

OIT. (2001). World employment: Life at work in the informal economy. Geneveve: ILO.

Pánuco, H. y Székely, M. (1999). La distribución del ingreso y la pobreza en México. El nuevo modelo económico en América Latina su efecto en la distribución del ingreso. En V. Bulmer-Thomas (Ed.), El Trimestre Económico. (pp. 225-266). México: FCE.

Pérez, R., Issamu, G. y Veras, F. (2010). El programa Tekoporã de transferencias monetarias de Paraguay: un debate sobre métodos de selección de beneficiarios. Revista de la CEPAL 100. Santiago de Chile. CEPAL, 209-221.

Perry, G.E., O. Arias, J.H.López, W.Malloney y L. Sérven. (2006) Poverty Reduction and growth: virtuos in vicious circle. Washington: The World Bank.

PNUD (2010). Informe regional sobre desarrollo humano para América Latina y el Caribe 2010. Disponible en: www.idhalc-actuarsobreelfuturo.org (Consultado el 08 de octubre del 2014).

Salinas, C. (1989). Programa nacional de solidaridad. México: Presidencia de México.

Schorrocks, A. (1980). The class of inequality measures aditivly decompensables. Econometrica, 48, 612-625.

Schorrocks, A. (1984). Inequality decomposition by population subgroups. Econometrica 52: 13691385. 
Schumpeter, J. (1975). Historia del análisis económico T-2. México: FCE.

Secretaría de Programación y Presupuesto (1982). Censo general de población y vivienda 1982. México.

Sedesol (2008). El programa Oportunidades. Reglas de operación. Disponible en: www.oportunidades.gob.mx (Consultado el 08 de Octubre del 2014).

Sedesol. (2003). Programa institucional Oportunidades 2002-2006. México: Secretaría de Desarrollo Social.

Seguro Popular (2001). Sistema nacional de protección en salud. Disponible en:.http://www.salud. gob.mx/transparencia/inform adicional/InfoGralSP.pdf (Consultado el 08 de octubre del 2014).

Sen, A. (1996). Capacidades y bienestar. EnM. Nussbaum y A. Sen (Eds.), La calidad de vida (pp. 27-54). México: FCE.

Soria, V. (2001). El mercado de trabajo en Brasil y México a la luz de la integración internacional y la crisis financiera.Comercio exterior. México: BNCE.

Stiglitz, J. (2012). El precio de la desigualdad. Madrid: Taurus.

Szekely, M. (2005). Pobreza y desigualdad en México entre 1950 y 2005. Serie documentos de investigación. México: SEDESOL.

Tello, C. (2010). Sobre la desigualdad en México. México: UNAM.

Tello, C. (2009). Estado y desarrollo: México 1920-2006. México: UNAM.

Tockman, V. (1993). Mercados de trabajo y empleo en el pensamiento económico Latinoamericano. En O. Sunkel (Ed.), El desarrollo desde adentro (pp. 163-191). México: FCE.

UNDP. (2002). Human development report. New York: UN.

UNDP (2014). Human development report, sustaining human progress: Reducing. Vulnerabilities and building resilence. Disponible en: http://hdr.undp.org/es (Consultado el 10 de marzo 2015).

United Nations. (2000). A better world for all. New York: UN.

USA, Labor Department (2014 y 2009). Unemployment statistics. Washington, DC.

Valero-Gil, J. y M. Valero (2008). The effects of rising food prices on poverty in Mexico. U of M-dearborn. 22. August: MPRA, JEL, UANL.

Varella A. y Cabral M. (2007). Productivity effects on Mexican manufacturing. Employment before and after NAFTA, CID Working Paper No. 152. Cambridge: Harvard University.

Villareal, R. (1988). Deuda externa y política de ajuste: el caso de México 1982-1986. En: S. Griffith (Ed.), Deuda externa, renegociación y ajuste en la América Latina, (pp. 42-67). FCE Lecturas 61. México: El Trimestre Económico

The World Bank (2013). Inequality in focus. Disponible en: http://www.worldbank.org/content/dam/ Worldbank/document/Poverty\%20documents/inequality-in-focus-october2013-v12.pdf (Consultado el 23 de enero del 2015).

The World Bank (2005). World development report. Washington D.C.

Zabludovsky, J. (1992). Liberalización comercial y ajuste macroeconómico. En D. Brothers y L. Solís (Eds.), México en busca de una nueva estrategia de desarrollo (74) (pp. 160-180). México: El Trimestre Económico, FCE Lecturas.

Zedillo, E. (1995). Programa educación. In Salud y Alimentación. México: Presidencia. 